\title{
Preserved Learning and Memory in Amnesia: Intact Adaptation-Level Effects and Learning of Stereoscopic Depth
}

\author{
William C. Benzing \\ Department of Neurosciences \\ University of California School of Medicine, San Diego
}

\author{
Larry R. Squire \\ Veterans Administration Medical Center, San Diego \\ and Department of Psychiatry \\ University of California School of Medicine, San Diego
}

\begin{abstract}
Amnesic patients and control Ss performed similarly on 2 memory tests. In Experiments $1 \mathrm{~A}$ and 1B, amnesic patients exhibited intact adaptation-level effects: An experience lifting and judging a group of weights influenced their judgments of a 2 nd group of weights 20-25 min later. The effect did not depend on peripheral accommodation, because Ss used 1 hand during their 1st encounter with the weights and the opposite hand during their 2 nd encounter. In Experiment 2, amnesic patients acquired at a normal rate the ability to perceive binocular depth using random-dot stereograms. In both experiments, amnesic patients benefited from recent experience, despite the fact that they could not remember their prior experience accurately. The preserved memory abilities demonstrated here appear to be examples of implicit, or nondeclarative, memory.
\end{abstract}

The study of human amnesia can provide useful information about the structure and organization of normal memory (Baddeley, 1982; Cermak, 1982; Hirst, 1982; Schacter, 1985; Squire, 1986; Weiskrantz, 1987). Amnesia is evident as a severe impairment on tests that assess free recall, cued recall, or recognition of recently encountered facts or events. Immediate memory is typically intact, as is general intellectual capacity, personality, and remote memory for the distant past. Despite the severe memory impairment, it is now known that some kinds of learning and memory are spared. Amnesic patients have a preserved capacity for several kinds of skill learning (Brooks \& Baddeley, 1976; Cohen \& Squire, 1980; Milner, 1962; Nissen \& Bullemer, 1987). They also exhibit normal priming effects (for a review, see Shimamura, 1986). These preserved capacities for learning can occur in amnesic patients without awareness of prior study sessions and without recognition, as measured by formal tests, of the previously presented material.

These results have suggested a distinction between two or more memory processes or systems (Cohen, 1984; Schacter, 1987; Squire, 1982; Squire \& Zola-Morgan, 1988). One form of memory affords the ability to store information so that it is available later as a conscious recollection. It includes the facts, lists, and data of everyday life and conventional mem-

The research was supported by the Medical Research Service of the Veterans Administration, National Institute of Mental Health Grant MH24600, the Office of Naval Research, and National Institutes of Health Training Grant GM08107.

We thank Joyce Zouzounis and Kim Rivero-Frink for research assistance, and B. Julesz and V. Ramachandran for advice.

Correspondence concerning this article should be addressed to Larry R. Squire, Veterans Administration Medical Center (116 A), 3550 La Jolla Village Drive, San Diego, California 92161. ory tests. This kind of memory, termed declarative, is dependent on the brain regions damaged in amnesia. It can be declared (i.e., brought to mind as a proposition or an image). By contrast, the abilities so far demonstrated to be spared in amnesia are examples of implicit memory abilities. The information is accessible through performance and does not appear to depend on declarative knowledge about a previous experience. For example, in the case of skill learning, subjects seem to access the information by engaging in the procedures in which the knowledge is embedded. The term procedural aptly describes skill learning, but it is not clear whether the same term usefully describes other spared learning abilities in amnesia. Little is known about the similarities and differences between spared abilities (e.g., skill learning and priming) or about the potential for finding other examples of spared learning. Additional demonstrations of preserved learning ability in amnesic patients could illuminate these issues of classification.

Recently, it was reported that initially unfamiliar melodies became more preferred following brief exposures to the melodies (Johnson, Kim, \& Risse, 1985). A similar shift in preference occurred in both amnesic patients and control subjects, despite the fact that the amnesic patients were poor at recognizing the melodies that had been presented. The literature of the adaptation-level phenomenon provides additional examples of how perception can be influenced by recent experience. Adaptation-level effects refer to the finding that experience with one set of stimuli influences how a second set of stimuli are perceived (Helson, 1947, 1948). One's experience with a particular class of stimuli appears to establish a set or a bias that modifies how other members of the same class are subsequently perceived. Little work has been done to determine whether these effects typically persist beyond the minute or two required to judge one set of stimuli 
and then another; little is also known about the role of conscious, declarative knowledge in adaptation-level effects. Nevertheless, the adaptation-level phenomenon is robust, having been observed in the visual (Helson, 1948; Helson \& Michels, 1948), auditory (Johnson, 1949; Long, 1937; Pratt, 1933), and tactual (Dinnerstein, 1965; Helson, 1947; Tresselt, 1947) modalities. In Experiments $1 \mathrm{~A}$ and $1 \mathrm{~B}$ we examined whether adaptation-level effects in the tactual modality can persist across a 20-min interval and whether amnesic patients exhibit these effects to the same extent as do normal subjects. To ensure that any effects observed would reflect changes in the central nervous system, not peripheral accommodation, adaptation-level effects were assessed across the two hands.

A second kind of learning that seems likely to be implicit and independent of declarative memory strategies is the perceptual learning of stereoscopic, binocular depth. Perception of random-dot stereograms is greatly facilitated by prior experience with different stereograms (Goryo \& Kikuchi, 1971; Julesz, 1971) or by repeated exposures to the same stereogram (Julesz, 1971; MacCracken \& Bourne, 1977; MacCracken \& Hayes, 1976; Ramachandran, 1976).

It has been proposed that this learning is stored in the same areas of visual cortex that are involved in performing stereoscopic perception (Ramachandran, 1976). If so, it would possess a feature thought to be important in other examples of skill (procedural) learning - the learning is intrinsic to the systems engaged during performance (Squire, 1987)-and it might well be preserved in amnesia. Weiskrantz and Warrington (1979) cited unpublished observations by Ramachandran involving 2 amnesic patients who reportedly showed good learning and retention of this ability. In Experiment 2 we examined whether amnesic patients are facilitated as much as control subjects by prior experience with random-dot stereograms and whether this facilitation occurs in the absence of explicit, declarative memory for the learning experience.

\section{Experiment $1 \mathrm{~A}$}

A weight judgment task (Tresselt, 1947) was used to determine whether amnesic patients exhibit normal adaptation-level effects.

\section{Method}

\section{Subjects}

Amnesic patients. Ten amnesic patients were tested: 5 men and 2 women with alcoholic Korsakoff's syndrome, 2 men with amnesia caused by an anoxic episode, and 1 woman with amnesia caused by a bilateral thalamic infarction. The patients with Korsakoff's syndrome resided in supervised facilities in San Diego County. Six of them have been described in detail previously (Patients K1-K6 in Squire \& Shimamura, 1986). Of the 2 patients with amnesia caused by an anoxic episode, 1 became amnesic in 1976 following cardiac arrest, and the other became amnesic in 1984 when respiratory arrest occurred during an epileptic seizure (see Cases A.B. and L.M. in Squire \& Shimamura, 1986). The remaining patient (Case M.G.) became amnesic in 1986 following a thalamic infarction. In the present study, the results obtained for patients with Korsakoff's syndrome were identical to the results for the other amnesic patients. Accordingly, we present the patients here as a single group.

The 10 amnesic patients averaged 55.4 years of age and 12.9 years of education. They had an average Wechsler Adult Intelligence ScaleRevised (WAIS-R) IQ score of 103.5. On the newly available Wechsler Memory Scale-Revised (WMS-R; Butters et al., 1988; Wechsler, 1987), index scores were as follows: Attention and Concentration = 96.1, Verbal Memory $=72.5$, Visual Memory $=76.2$, General Memory $=67.6$, and Delayed Memory $=56.2$. Immediate and delayed recall $(12 \mathrm{~min})$ of a short prose passage averaged 5.6 and 0 segments, respectively ( 21 segments total). Average scores for copy and delayed recall (12 min) of a complex diagram (Lezak, 1983; Osterrieth, 1944) were 27.7 and 5.1 segments, respectively ( 36 segments total). Pairedassociate memory of 10 unrelated noun-noun pairs on each of three successive trials was $0.5,0.3$, and 1.5. Free recall of 15 words (Lezak, 1983; Rey, 1964) averaged 3.5, 4.7, 5.3, 5.0, and 5.2 on five successive study/test trials. For yes-no recognition of 15 old words and 15 new words, the average score on five successive study/test trials was 21.5, 24.6, 24.9, 25.8, and 26.9.

Neuropsychological screening and independent neurological examination indicated that memory impairment was the only remarkable deficit of higher cortical function. The amnesic patients averaged 133.2 points out of a possible 144 points on the Dementia Rating Scale (Mattis, 1976). All patients could draw a cube and a house in perspective, and none had aphasia or apraxia. Additional neuropsychological data for 8 of these 10 patients $(6$ of the 7 Korsakoff patients and cases A.B. and L.M.), plus scores for control subjects on all the tests just reviewed, can be found elsewhere (Squire \& Shimamura, 1986).

Control subjects. We tested 11 healthy control subjects ( 7 men and 4 women) who were volunteers or employees at the San Diego Veterans Administration Medical Center. They were matched to the 10 amnesic patients with respect to age, education, and intelligence test subscores. They averaged 54.0 years of age, had 13.6 years of education, and had WAIS-R subtest scores of 21.6 for Information (19.3 for the 10 amnesic patients) and 53.2 for Vocabulary ( 52.9 for the 10 amnesic patients). Immediate and delayed recall $(12 \mathrm{~min})$ of a short prose passage averaged 7.0 and 6.5 segments, respectively.

\section{Materials}

Three sets of 10 cylindrical, plastic medicine containers (radius $=$ $1 \mathrm{in}$. $[2.54 \mathrm{~cm}]$, height $\left.=2 \frac{1}{4} \mathrm{in} .[5.72 \mathrm{~cm}]\right)$ were filled with lead shot and packed with cotton. Each set of 10 containers was identical except for their color (gray, brown, or black). The coloring served to obscure the contents of the containers and identified each set. All 10 containers in each of the three sets were identical in appearance, differing only in weight: $20 \mathrm{~g}, 70 \mathrm{~g}, 120 \mathrm{~g}, 170 \mathrm{~g}, 220 \mathrm{~g}, 270 \mathrm{~g}, 320$ $\mathrm{g}, 370 \mathrm{~g}, 420 \mathrm{~g}$, and $470 \mathrm{~g}$. One colored set of weights was assigned to each of 3 test days, as described in the Procedure section, such that all subjects received the same colored set of weights on the 1st test day, a different colored set on the 2 nd test day, and the third colored set on the final test day.

A 9-point scale was used for rating the weights. The numbers 1 to 9 were printed on a card from left to right, and each number was placed beneath a verbal descriptor ranging from extremely light (1) through medium (5) to extremely heavy (9). An eight-item questionnaire was also constructed to test recall and recognition memory for the task. The questions progressed from general to more detailed (see Table 1). For recognition memory, four alternatives printed on a card were presented to the subject. Five recognition choices were initially available. If a subject responded incorrectly during the recall phase with one of the recognition choices, that alternative was dis- 
Table 1

Questionnaire Used in Experiment $1 \mathrm{~A}$

1. What type of test did we do first today?

2. What did the weights look like?

3. What color were the weights?

4. How did you report your judgment of how heavy a weight was?

5. What was the range of the scale you used?

6. How many inches off the table were you asked to lift the weights?

7. How many different weights did you tell me that you judged?

8. Between which fingers did I ask you to grasp each weight?

carded from the recognition test. Otherwise, one of the four incorrect choices was randomly omitted from the recognition test.

\section{Procedure}

Subjects were told that they were being tested for their ability to judge weights. To make judgments, they were asked to grasp each container between their thumb and forefinger, to lift it approximately 4-5 in. off the table while keeping their elbow on the table, and then to return the container to the table. At that point, subjects were asked to make a weight judgment according to one of the verbal descriptors on the 9-point rating scale, which was in view throughout the session.

Three conditions (light bias, no bias, and heavy bias) were presented on 3 separate days during 1 week (on Days 1, 2, and 7). The order of the conditions was counterbalanced across subjects. Each condition consisted of 40 bias trials followed $20-25 \mathrm{~min}$ later by 10 test trials. That is, in every condition subjects lifted 40 containers and provided 40 ratings and then after $20-25 \mathrm{~min}$ lifted 10 containers and provided 10 more ratings. Only one container at a time was in the subject's view. For the light-bias and heavy-bias conditions, each of the 5 lightest or 5 heaviest containers was presented eight times. For the no-bias condition, all 10 containers were presented four times each. All subjects in each condition were presented 40 containers in the same fixed random order with the constraint that each container was presented before any container was repeated.

During the 40 bias trials on the 1st test day, half of the subjects used their preferred hand and the other half used their nonpreferred hand. For individual subjects, the use of preferred or nonpreferred hand during the 40 bias trials alternated across the 3 test days. During the interval between the 40 bias trials and the 10 test trials, subjects were given the random-dot stereogram task as described in Experiment 2.

For the 10 test trials, subjects were told that this was another test of their ability to judge weights. Subjects were instructed that they would receive another series of weights, which were to be lifted and rated as before. For the test trials, subjects used the hand opposite to the hand used during the bias trails. Each of the 10 weights was presented once in a fixed random order for a total of 10 presentations. The 10 test trials were identical on all 3 test days.

On the 1 test day only, subjects were also given the eight-item questionnaire just prior to the 10 test trials. Questions were read aloud. If a subject answered the recall question incorrectly, the same question was presented again in a four-choice, multiple-choice format. If a subject still chose incorrectly, the correct answer was provided. When correct answers were given, subjects were told that they were correct.

\section{Results}

Figure-1 shows performance on the bias trials of the weight judgment task. Ratings for the 40 trials were averaged for each subject within each bias condition (light bias, no bias, and heavy bias). A $2 \times 3$ analysis of variance (ANOvA; Group $\times$ Bias Condition) showed that judgments were markedly affected by the bias condition (i.e., by how light or heavy the containers were), $F(2,38)=105.1, p<.001$. Amnesic patients and control subjects performed similarly, $F(1,19)=$ $0.08, p>.1$, and there was no Group $\times$ Condition interaction, $F(2,38)=0.03, p>.1$.

Figure 2 shows performance on the 10 test trials. Ratings for the 10 trials were averaged for each subject within each bias condition (light bias, no bias, and heavy bias). A $2 \times 3$ ANOVA (Groups $\times$ Bias Condition) showed that the bias condition significantly influenced how the 10 test weights were judged, $F(2,38)=26.35, p<.001$. When subjects lifted relatively light weights (light-bias condition), they subsequently judged the 10 test weights to be relatively heavy. By contrast, when subjects lifted relatively heavy weights (heavybias condition), they subsequently judged the same 10 test weights to be relatively light. Amnesic patients and control subjects performed similarly overall, $F(1,19)=0.002, p>$ .1 , and there was no Group $\times$ Bias interaction, $F(2,38)=$ $1.66, p>.1$. Separate analyses by group showed that both the amnesic patients and the control subjects were strongly influenced by the bias condition ( $F \mathrm{~S}\rangle 12.3, p=<.001$ ). Additional analyses showed that performance was similar across the 3 test days, $F(2,38)=1.56, p>.1$, and that there

\section{BIAS TRIALS}

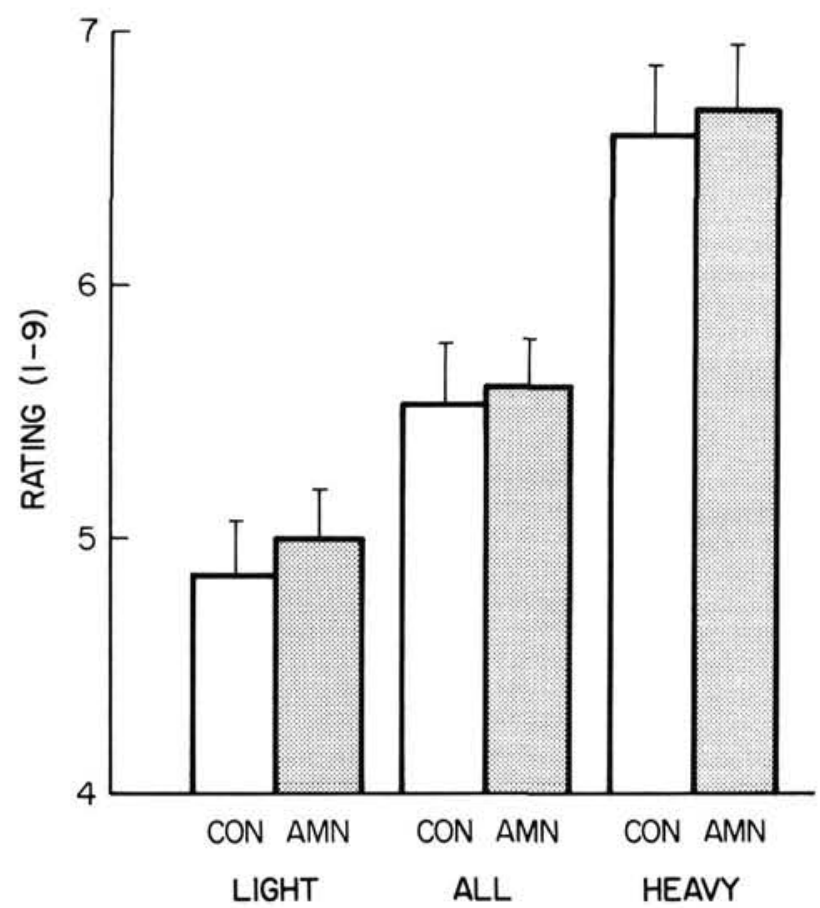

Figure 1. Mean ratings (1-9 scale) by amnesic patients (AMN; $N$ $=10)$ and control subjects $(\mathrm{CON} ; N=11)$ for 40 weights presented during the bias trials of the weight task. (Subjects judged either the 5 lightest weights [ 8 times each], all 10 weights [ 4 times each], or the 5 heaviest weights [ 8 times each]. Brackets show standard error of the mean.) 


\section{IO TEST TRIALS}

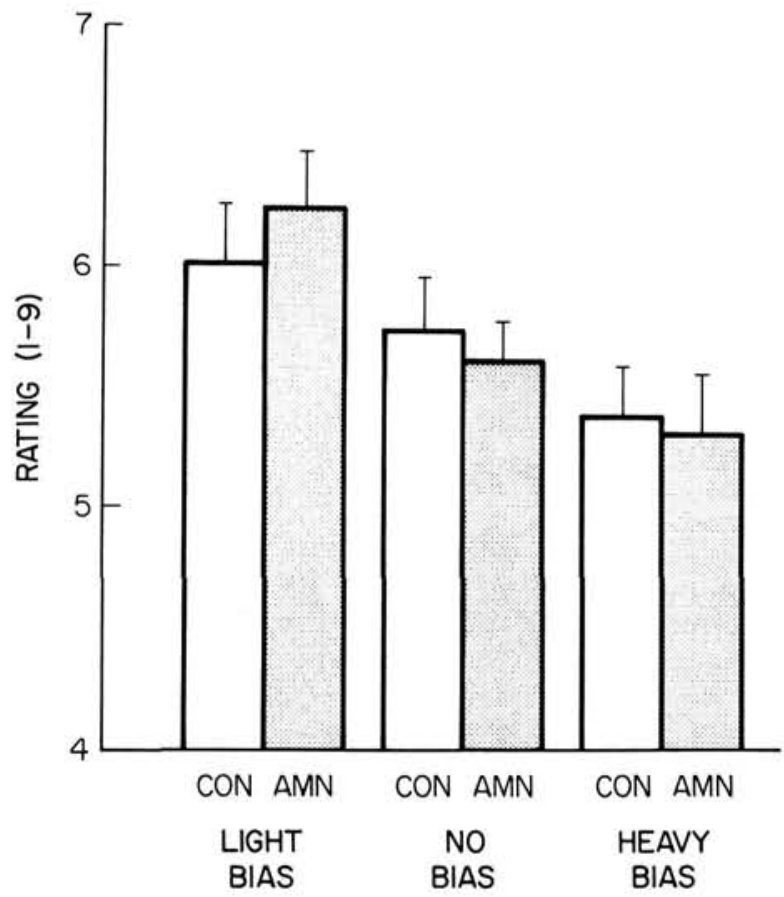

Figure 2. Mean ratings (1-9 scale) by amnesic patients (AMN; $N$ $=10$ ) and control subjects (CON; $N=11$ ) for the 10 weights presented during the test trials of the weight task. (Judgments of these 10 weights were influenced according to whether subjects had 20$25 \mathrm{~min}$ previously lifted light weights [light bias], heavy weights [heavy bias], or both light and heavy weights [no bias]. Brackets show standard error of the mean.)

was no Group $\times$ Test Day interaction, $F(1,19)=0.002, p$ $>$.1. Finally, we examined the individual ratings given by each subject for each of the 10 test weights. Within each bias condition, there were no group differences nor Group $\times$ Test Trial interactions $(F \mathrm{~s}<1.11, p>.1)$ in how the 10 test weights were rated.

Although the amnesic patients exhibited intact adaptationlevel effects $20-25 \mathrm{~min}$ after the bias trials, they remembered the bias trials poorly at this time (Figure 3). Performance of the amnesic patients was impaired relative to control subjects both on the recall, $t(18)=6.2, p<.001$, and on the recognition portions of the eight-item questionnaire, $t(18)=5.8$, $p<.001$. The amnesic patients averaged $41.3 \%$ correct for recall (control subjects $=85.2 \%$ ) and $68.8 \%$ correct for recognition (control subjects $=96.6 \%$, chance $=25.0 \%$; subjects who answered correctly on the recall test were given credit for that question on the recognition test). Finally, the $5 \mathrm{am}$ nesic patients who obtained the best scores on the recall and recognition tests performed about the same on the rating task (average for light-bias condition $=6.4$; heavy bias $=5.4$ ) as the 5 patients who obtained the poorest scores on the recall and recognition tests (average for light-bias condition $=6.0$; heavy bias $=5.2$ ).
Additional informal observations also attested to the poor memory that the amnesic patients had for the bias trials, even as they were exhibiting the influence of those trials in their ratings. For example, 9 of the 10 amnesic patients needed to be reminded during at least one test session to keep their elbow on the table while lifting the weights. The same 9 patients also had to be reminded to report the verbal descriptors on the rating scale rather than the numbers, and 8 had to be reminded how high to lift the weights. By contrast, only 1 control subject needed reminding to keep his elbow on the table; none needed reminding about how to report the ratings; and 2 needed a reminder about how high to lift the weights.

\section{Experiment 1B}

In this experiment we investigated whether the biasing effect observed in Experiment $1 \mathrm{~A}$ was dependent on having previous experience with the rating scale. It seemed possible that subjects might remember the ratings they used on the bias trials. Alternatively, subjects might form a preference for certain ratings on the basis of their experience with them. In either case, experience using ratings on the bias trials could conceivably affect which ratings were used during the subsequent test trials. If this occurred, then a shift in the mean weight rating as a function of the bias condition could not be interpreted unambiguously as a change in perceived weight.

To evaluate this possibility, we investigated whether shifts in the mean weight rating would also occur when subjects had no previous experience with the rating scale. Subjects were given either a light- or heavy-bias condition as in Ex-

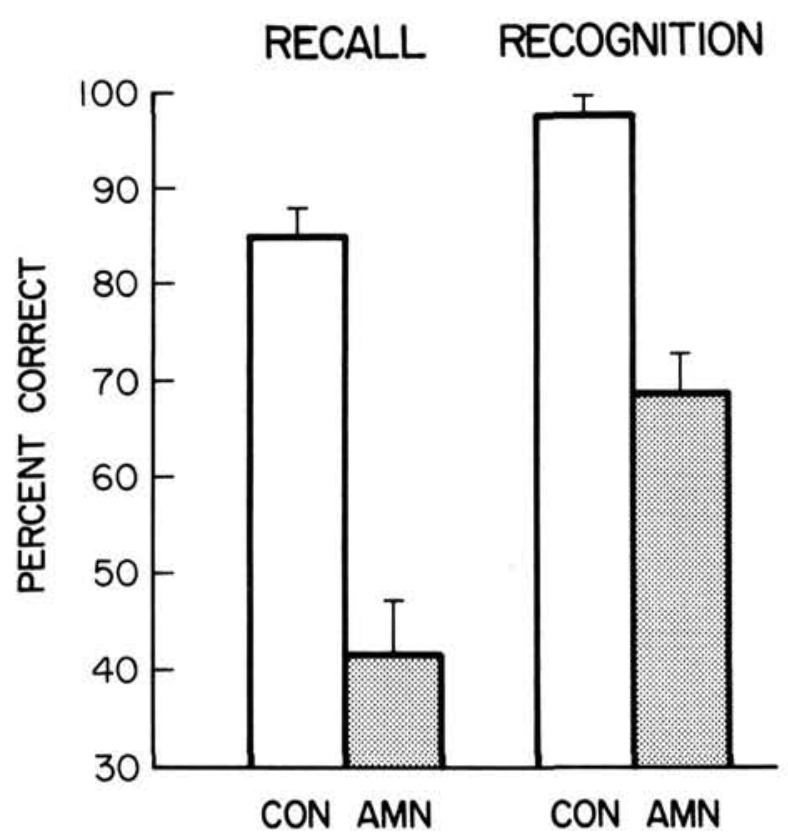

Figure 3. Memory of the weight judgment task as assessed by an eight-item questionnaire given $20-25 \mathrm{~min}$ after completion of the 40 bias trials on the 1st test day. (Brackets show standard error of the mean. $A M N=10$ amnesic patients; $\mathrm{CON}=11$ control subjects.) 


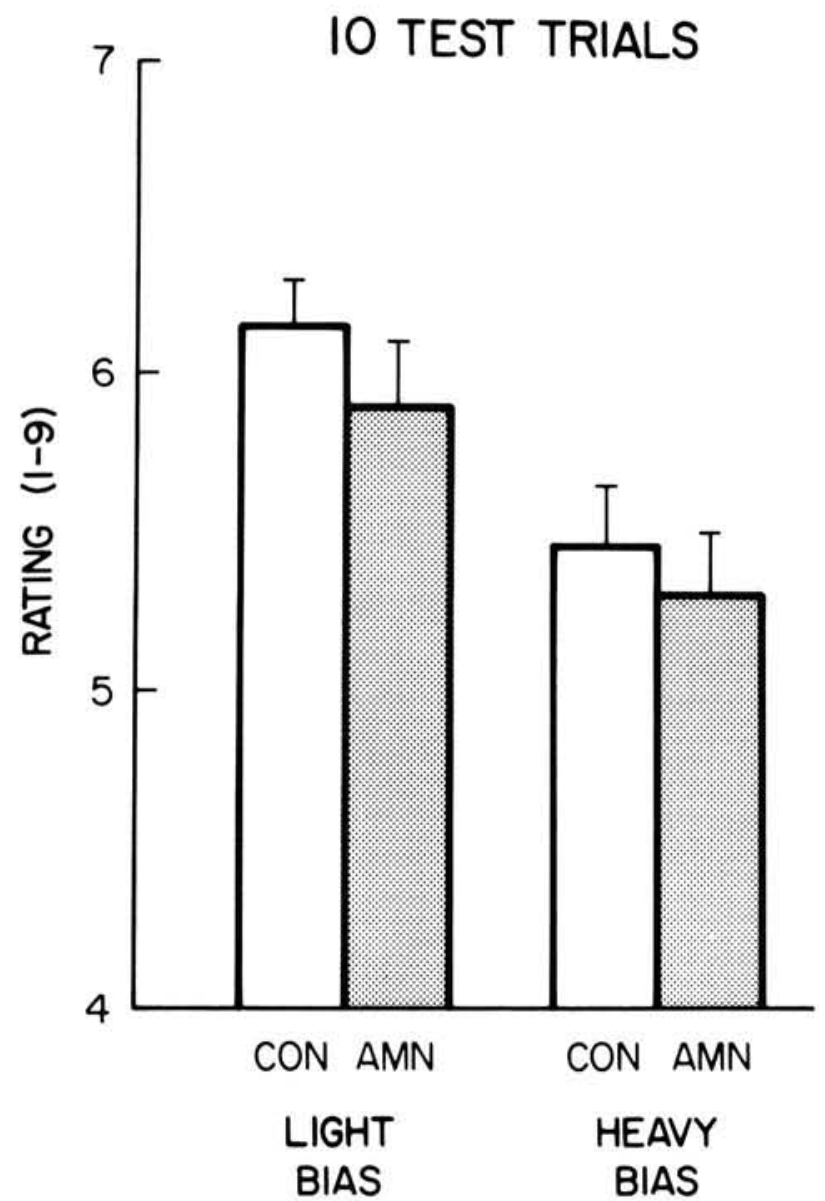

Figure 4. Mean ratings (1-9 scale) by amnesic patients (AMN; $N$ $=8)$ and control subjects ( $C O N ; N=11)$ for the 10 weights presented during the test trials of the weight task. (Judgments of these 10 weights were influenced according to whether subjects had 20-25 min previously lifted light weights [light bias] or heavy weights [heavy bias]. Brackets show standard error of the mean.)

periment $1 \mathrm{~A}$. However, instead of using the rating scale, subjects were asked to judge whether each weight was heavier or lighter than the immediately preceding weight. Twenty to $25 \mathrm{~min}$ later, 10 test weights were presented for rating on the 1-9 scale, just as in Experiment 1A.

\section{Method}

\section{Subjects}

Amnesic patients. Eight of the 10 amnesic patients described in Experiment 1A participated in Experiment 1B. The 2 patients not tested were K3 (see Squire \& Shimamura, 1986) and M.G. The 8 patients averaged 56.1 years of age, 13.0 years of education, and had an average WAIS-R IQ score of 100.8. Testing in Experiment $1 B$ occurred from 5.5 to 6.25 months after the completion of Experiment IA.

Control subjects. Eleven new healthy control subjects (4 men and 7 women) who were volunteers or employees at the San Diego Veterans Administration Medical Center were also tested. They were matched to the amnesic patients with respect to age, education, and intelligence test subscores. They averaged 55.9 years of age, had 13.5 years of education, and had WAIS-R subtest scores of 21.1 for Information (20.3 for the patients) and 51.6 for Vocabulary (54.4 for the patients). Immediate and delayed recall $(12 \mathrm{~min})$ of a short prose passage averaged 8.0 and 6.5 segments, respectively.

\section{Materials}

Two sets of the weights described in Experiment $1 \mathrm{~A}$ were used. Each set consisted of 10 containers that were identical in every respect except their weight $(20-470 \mathrm{~g}$ in $50-\mathrm{g}$ steps).

\section{Procedure}

Subjects were told that they would lift a container and that another container would then be presented for lifting. Their task was to judge whether the second container was heavier or lighter than the first container. It was explained further that there would be additional containers to lift and that subjects were to judge whether each container was heavier or lighter than the immediately preceding one. Only one container at a time was in the subject's view.

Two conditions (light bias and heavy bias) were presented on 2 separate days during 1 week (the mean interval between conditions was 3.5 days; range $=1-7$ days). The order of the conditions was counterbalanced across subjects. Each condition consisted of 40 bias trials (for the light-bias condition, each of the 5 lightest containers was presented eight times; for the heavy-bias condition, each of the 5 heaviest containers was presented eight times). With the exception of the rating task, the bias trials were conducted exactly as in Experiment $1 \mathrm{~A}$. Twenty to $25 \mathrm{~min}$ after the bias trials, subjects received 10 test trials, which consisted of a single presentation of each of the 10 containers. The test trials were conducted exactly as in Experiment $1 \mathrm{~A}$ (i.e., subjects were asked to rate the weight of each container on a $1-9$ scale).

Half of the subjects in each group used their preferred hand on the bias trials of the 1st test day and the nonpreferred hand for the bias trials of the $2 \mathrm{nd}$ test day. The other half of the subjects used their nonpreferred hand first and then their preferred hand. For the test trials, subjects always used the hand opposite to the hand used for the bias trials.

At the end of the 10 test trials on the 2nd test day, all of the amnesic patients and 7 of the 11 control subjects were asked whether they thought their ratings on the test trials had been influenced by the bias trials. They were also asked whether the weights presented on the test trials were the same as or different from the weights presented on the bias trials. Subjects who thought the weights were different were asked to report in what way they were different.

\section{Results}

The amnesic patients and control subjects performed similarly on the judgment task, achieving scores of 36.0 and 36.8 correct, respectively, on the light-bias trials and 35.0 and 34.7 correct, respectively, on the heavy-bias trials (maximum possible score $=39$ ). Figure 4 shows performance on the 10 test trials. Ratings for the 10 test weights were averaged for each subject within the two bias conditions (light and heavy). A $2 \times 2$ ANOva (Group $\times$ Bias Condition) showed that the bias condition markedly affected how the 10 test weights were judged, $F(1,17)=24.9, p<.001$. Amnesic patients and control subjects performed similarly, $F(1,17)=0.76, p>$ .1 , and there was no Group $\times$ Bias Condition interaction, $F(1,17)=0.75, p>.1$. Separate analyses showed that each 
subject group was strongly influenced by the bias condition: amnesic patients, $F(1,7)=8.45, p<.01$; control subjects, $F(1,10)=16.7, p<.01$. Finally, comparison of Figures 2 and 4 shows that subjects performed similarly whether they did (Figure 2) or did not (Figure 4) use the rating scale during the bias trials.

Seven control subjects and 8 amnesic patients were interviewed after the test trials on the 2 nd test day. Six of the control subjects and 2 of the amnesic patients thought that their ratings on the test trials had been based to some extent on their memory for the bias trials. However, subjects' declarative knowledge about the relation between the bias trials and the test trials was poor. Only 2 subjects ( 1 in each group) correctly stated that the weights on the test trials had been on average heavier (or lighter) than the weights on the bias trials. Six subjects ( 3 in each group) stated that the weights were the same on the bias and test trials; 3 subjects in the amnesic group stated that the weights were heavier (or lighter) on the test trials when in fact the opposite was true; 3 subjects in the control group stated incorrectly that some of the weights on the test trials were heavier than the weights on the bias trials and that some of the weights were lighter; and 1 amnesic patient stated that the weights were different but could not say how they were different.

\section{Experiment 2}

In Experiment 2 we examined whether amnesic patients could demonstrate learning and retention of the ability to perceive random-dot stereograms.

\section{Method}

\section{Subjects}

The same 10 amnesic patients and 11 control subjects who were tested in Experiment $1 \mathrm{~A}$ also served as subjects in Experiment 2.

\section{Materials}

Fifteen unique random-dot stereograms, taken from Julesz (1971), were divided into three sets of 5 each and mounted on cardboard. The stereograms consisted of simple geometric figures or letters (e.g. $T$, square, triangle). The stereograms were placed in a viewing apparatus constructed from a cardboard box with the top and one side removed. A stereopsis viewing assembly (Kaufman, 1974) was mounted such that the lenses formed the border of the open side of the box. The lenses were placed $51 / 4$ in. $(13.34 \mathrm{~cm})$ from the stereograms, and a vertically oriented divider prevented binocular vision of either half of the stereograms. The top of the box was open to overhead room light.

An eight-item questionnaire was constructed to test memory for the task. The questions progressed from general to more detailed (see Table 2). Each question was first asked in a recall format and then in a four-choice recognition format, just as described for the weight task questionnaire in Experiment $1 \mathrm{~A}$.

\section{Procedure}

Three sets of stereograms (five in each set) were presented on 3 different days (Days 1,2, and 7). The order of presentation of the
Table 2

Questionnaire Used in Experiment 2

1. Yesterday, we did two different tests. One test involved judging weights. What did we do in the other test?

2. What did the viewing apparatus look like?

3. What did you do with the viewing apparatus?

4. What were the figures that you viewed with the apparatus?

5 . How many different figures did you view yesterday?

6. What color were the designs?

7. Can you name two of the figures that you saw yesterday?

8. What kind of perception did I tell you that this test tested?

three sets was counterbalanced across subjects. The five stereograms within a set were always presented in the same order. The task was administered during the 20-25 min interval that separated the bias and test trials of Experiment $1 \mathrm{~A}$.

Subjects were told that they were receiving a test of their ability to see in depth. They were told what kind of figures they should expect to see (e.g., simple geometric figures or letters) and that the figure to be identified would at some point "pop out" at them and appear to stand above the background. Subjects were also told that it might take a fair amount of time for this to occur and that they should report the figure to the experimenter as soon as it could be identified. Subjects were given general encouragement as they viewed the stereograms, including reminders to report the figure as soon as possible. Response time was measured with a digital stopwatch. If after $180 \mathrm{~s}$ a subject could not identify the figure, that trial was concluded and the next stereogram was offered for viewing.

On the 2nd day of testing only, subjects were given the eight-item questionnaire just prior to the stereogram task. The questionnaire was given just as described in Experiment $1 \mathrm{~A}$.

\section{Results}

Figure 5 shows the time required to identify the stereograms on each trial and across the 3 test days. Julesz (1971) reported that approximately $8 \%$ of subjects are unable to perceive random-dot stereograms. Three (14\%) of our subjects ( 2 control subjects and 1 amnesic patient) were removed from the data analysis because of their inability to perceive the stereograms or to improve with practice. Of the 2 control subjects, one could not perceive any of the stereograms and the other perceived only the final $(15$ th) stereogram. The amnesic patient was able to identify only the 5th stereogram on each test day ( 3 out of 15 stereograms). In contrast to the performance of these subjects, the next worse score in our sample was obtained by an amnesic patient and a control subject who each were able to perceive 8 of the 15 stereograms within the allotted $180 \mathrm{~s}$.

A $2 \times 3 \times 5$ Anova (Group $\times$ Test Day $\times$ Trial) showed that performance improved markedly both within the five trials of each test day, $F(4,64)=21.4, p<.001$, and across the 3 test days, $F(2,32)=6.5, p<.01$. Amnesic patients and control subjects performed similarly, $F(1,16)=0.04, p>$ .1 , and there were no significant interactions involving the group factor, $F \mathrm{~s}<1.10, p>.1$. A significant Test Day $\times$ Trial interaction was found, $F(8,128)=3.66, p<.001$, indicating that the shape of the learning curves changed across test days.

Separate analyses compared performance between individual test days. Performance on the 2 nd test day was better 


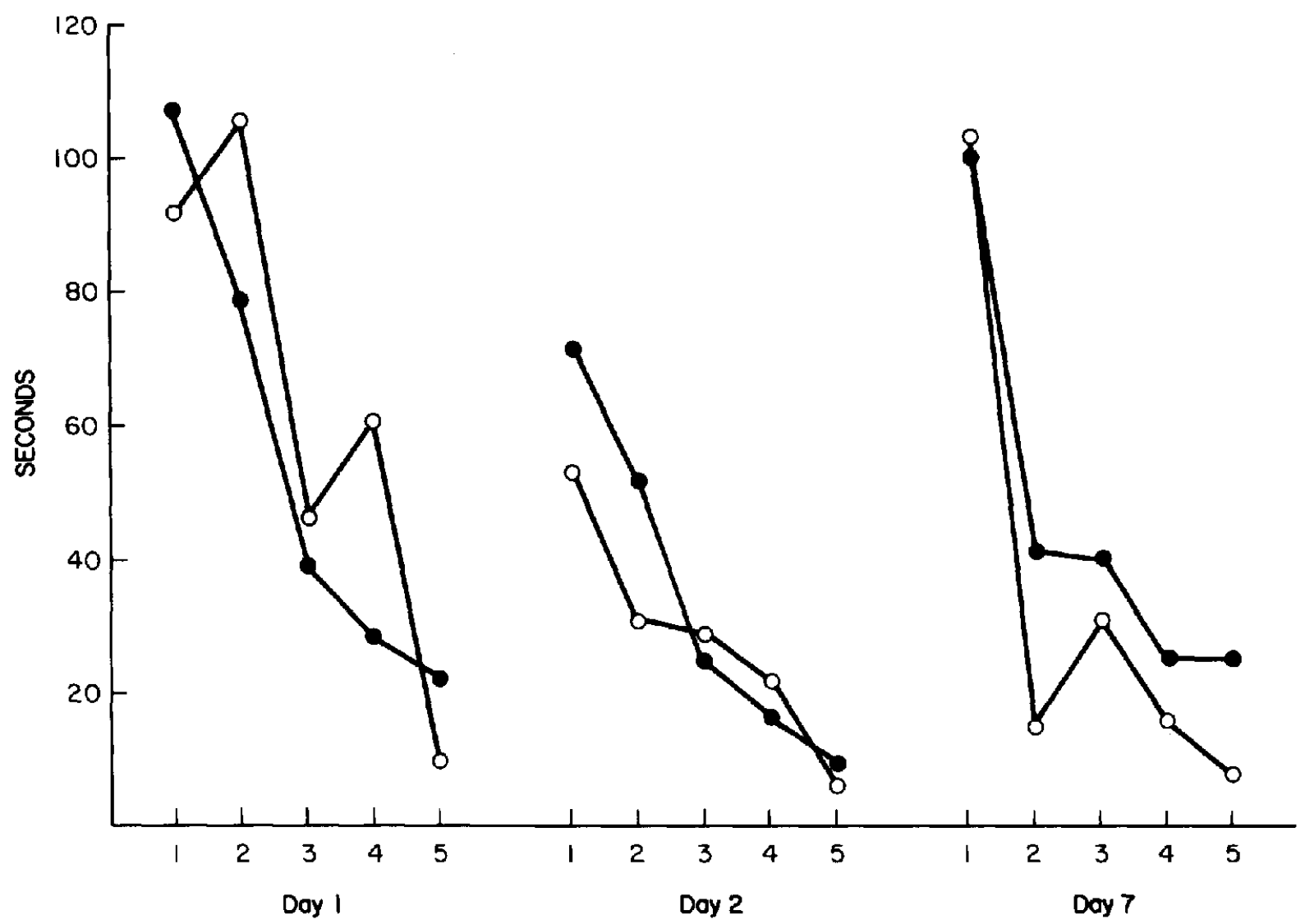

Figure 5. Mean response time (in seconds) per trial to identify random-dot stereograms. (Closed circles $=9$ amnesic patients; open circles $=9$ control subjects. The standard errors of the mean were similar for the two groups, averaging $18.4 \mathrm{~s}$ for the amnesic patients across the 15 data points [range $=3.9-28$ ] and $13.8 \mathrm{~s}$ for the control subjects [range $=1.3-25.7]$.)

overall than on the 1 st day: for control subjects, $F(1,8)=$ $8.81, p<.05$; for amnesic patients, $F(1,8)=4.63, p=.06$. One week later, the overall effect of practice was only marginally detectable; Day 1 vs. Day $7, F(1,16)=3.40, p=.08$. However, the shapes of the learning curves on Days 1 and 7 were markedly different: interaction of Test Day $\times$ Trial, $F(4,64)=5.89, p<.001$. Specifically, on the 1 st test day performance improved gradually across all five trials; in contrast, performance 1 week later was poor on the first trial and then much improved for the remaining trials. Separate analyses by group indicated that this effect was significant only for the control subjects. Nevertheless, in no comparisons between individual test days (Days 1 vs. 2, Days 1 vs. 7, and Days 2 vs. 7) were there any measurable group differences or interactions involving the group factor.

A final comparison was done to evaluate possible differences among the three different sets of stereograms. A $2 \times$ $3 \times 5$ ANova (Group $\times$ Stimulus Set $\times$ Trial) revealed no effect of test set, $F(2,32)=0.56, p>.1$, and no significant interactions involving the test set factor $(F \mathrm{~s}<1.45, p>.1)$.

Although the amnesic patients exhibited an intact ability to improve within trials and across test days, separate tests showed that they remembered the training experience poorly (Figure 6). Performance of the amnesic patients was impaired relative to control subjects both on the recall, $t(16)=7.57$, $p<.001$, and on the recognition portions of the eight-item questionnaire, $t(16)=5.98, p<.001$, which was given just prior to testing on the 2 nd day. The amnesic patients averaged $25.6 \%$ correct for recall (control subjects $=81.9 \%$ ) and $55.7 \%$ correct for recognition (control subjects $=93.1 \%$; chance $=25.0 \%$ ). Finally, the 4 amnesic patients who obtained the best scores on the recall and recognition tests performed about the same on the stereogram viewing task (the average time to see stereograms on each of 15 trials was $43.7 \mathrm{~s}$ ) as the 5 amnesic patients who obtained the poorest scores on the recall and recognition tests (the average time to see stereograms on each trial was $45.7 \mathrm{~s}$ ).

\section{Discussion}

In two different tasks, amnesic patients and control subjects exhibited a similar ability to benefit from past experience. In Experiments $1 \mathrm{~A}$ and $1 \mathrm{~B}$, amnesic patients showed normal adaptation-level effects. Like normal subjects, their judgments of perceived weight were influenced by prior experience with other weights. This effect could not be attributed to peripheral accommodation, because subjects used one hand during their first encounter with the weights and 


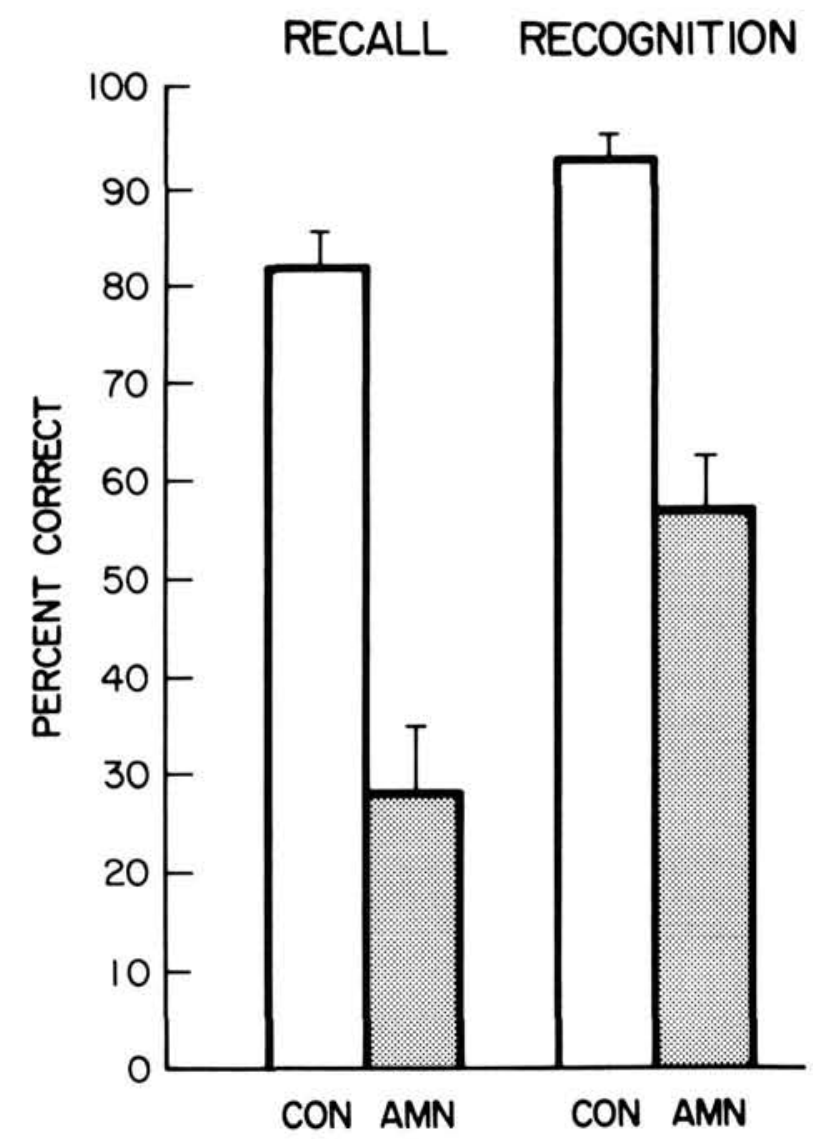

Figure 6. Memory of the random-dot stereogram task as assessed by an eight-item questionnaire given $24 \mathrm{hr}$ after test on the 1st day. (Brackets show standard error of the mean. AMN $=9$ amnesic patients; CON $=9$ control subjects.)

the other hand during their second encounter. The adaptation-level effect lasted at least $20-25 \mathrm{~min}$. Accordingly, this effect must lie outside of the province of immediate (e.g., digit span) memory, which is intact in amnesia. The possibility that the effective lifetime of immediate memory was extended by rehearsal was ruled out in Experiment 1A, because a second task intervened between the two encounters with the weights.

Experiment 1B showed that the adaptation-level effect did not depend on repeated experience with the rating scale. Simply lifting weights, and attending to their relative lightness and heaviness, influenced how other weights were rated 20-25 min later.

The adaptation-level effect observed here appears to be an example of implicit (Schacter, 1987), or nondeclarative (Squire \& Zola-Morgan, 1988), memory. This idea is supported by the finding that the amnesic patients did not remember their prior experience accurately, as measured by formal tests of recall and recognition memory. In particular, with two exceptions, neither the control subjects nor the amnesic patients could report accurately how the first group of weights (on the bias trials) differed from the second group of weights (on the test trials). Thus, experience with the first group of weights markedly influenced how the second group was judged, but this effect occurred in the absence of declarative knowledge about what had been learned.

In Experiment 2, amnesic patients exhibited intact learning of the ability to perceive stereograms. On the 1 st test day, they improved their ability across five trials, and they showed savings on the following day $(p=.06)$. Performance within days and across days was similar for amnesic patients and control subjects, despite the fact that the amnesic patients remembered the test sessions poorly from one day to the next. It seemed possible in principle that control subjects might be aided in this task by their ability to remember which test figures they had seen previously, because they could then try to perceive similar types of figures in the same location. Although the control subjects did sometimes perform numerically better than the amnesic patients (e.g., on the 3rd test day), the two groups could not be distinguished statistically.

Learning to perceive random-dot stereograms appears to be an example of perceptual skill learning, such as mirror reading (Cohen \& Squire, 1980). Learning to perceive stereograms developed gradually over many trials without declarative knowledge about how to accomplish the task. One possibility is that learning in these cases occurs as changes in the properties of the perceptual systems that are engaged by the task. Whereas mirror reading was performed well even 3 months after learning, the improved ability to perceive stereograms was only weakly evident 7 days after learning. This difference is probably due to the amount of initial training given in each case: 150 trials on 3 consecutive days in the case of mirror reading but only 10 trials on 2 consecutive days in the case of random-dot stereograms.

Adaptation-level effects appear to be distinct from skill learning in certain respects. Whereas skill learning leads ultimately to a new ability, adaptation-level effects result in some kind of average of the individual experiences. Each new stimulus adds to or subtracts from whatever has just preceded, and at any particular moment learning is effectively a running average of what has occurred previously. These cumulative effects laid successively on each other provide the basis for influencing subsequent perception apart from the ability to remember the individual encounters.

Our findings add two kinds of learning to the domain of preserved learning abilities exhibited by amnesic patients. Whereas declarative memory refers to a particular kind of memory that is impaired in amnesia, the learning that is preserved in amnesia may comprise a rather heterogeneous collection of abilities. Declarative memory depends on an interaction, established at he time of initial learning, between the hippocampus (and related structures) and putative memory storage sites in neocortex (Squire, Shimamura, \& Amaral, in press). This interaction affords the ability to remember new facts and episodes. Declarative memory is flexible, accessible to conscious recollection, and adapted for rapid, even one-trial learning.

By contrast, examples of intact learning in amnesia are collectively best described by a negative feature (they are nondeclarative), not by any positive feature that can be identified at this time. We have previously used the term procedural to describe these intact abilities. The term applies 
best to skill learning and may aptly describe other preserved abilities as well (e.g., word priming and classical conditioning), but their similarities and differences are understood so poorly that it may be better to refer to them specifically (Schacter, 1987, in press).

Nondeclarative memory appears to be embedded in specific procedures or is stored as tunings, biases, or activations. The information gained occurs as changes in particular perceptual systems or response systems, or as the development of specific production rules. In these cases, experience cumulates in behavioral change, but without necessarily requiring conscious recollection of either the learning episode itself or the information obtained from the episode. Nondeclarative memory is independent of the hippocampus and related structures that are damaged in amnesia. In some cases (e.g., priming, perceptual skill learning, adaptation-level effects), learning may be intrinsic to cortical structures that are engaged or activated by performing the tasks. In other cases (e.g., motor skill learning, classical conditioning), learning may depend on the participation of the extrapyramidal motor system (Mahut \& Moss, 1984; Mishkin, Malamut, \& Bachevalier, 1984; Thompson, 1986).

\section{References}

Baddeley, A. (1982). Implications of neuropsychological evidence for theories of normal memory. Philosophical Transactions of the Royal Society of London, B298, 59-72.

Brooks, D. N., \& Baddeley, A. D. (1976). What can amnesic patients learn? Neuropsychologia, 14, 111-122.

Butters, N., Salmon, D., Cullum, M., Cairns, P., Troster, A., Jacobs, D., Moss, M., \& Cermak, L. (1988). Differentiation of amnesic and demented patients with the Wechsler Memory Scale-Revised. The Clinical Neuropsychologist, 2, 133-148.

Cermak, L. S. (1982). Human memory and amnesia. Hillsdale, NJ: Erlbaum.

Cohen, N. J. (1984). Preserved learning capacity in amnesia: Evidence for multiple memory systems. In L. R. Squire \& N. Butters (Eds.), The Neuropsychology of memory (pp. 83-103). New York: Guilford Press.

Cohen, N. J., \& Squire, L. R. (1980). Preserved learning and retention of pattern analyzing skill in amnesia: Dissociation of "knowing how" and "knowing that." Science, 210, 207-209.

Dinnerstein, D. (1965). Intermanual effects of anchors on zones of maximal sensitivity in weight discrimination. American Journal of Psychology, 78, 66-74.

Goryo, K, \& Kikuchi, T. (1971). Disparity and training in stereopsis. Japanese Psychological Research, 13, 148-152.

Helson, H. (1947). Adaptation-level as frame of reference for prediction of psychophysical data. American Journal of Psychology, $60,1-29$.

Helson, H. (1948). Adaptation-level as a basis for a quantitative theory of frames of reference. Psychological Review, 55, 297-313.

Helson, H., \& Michels, W. C. (1948). The effect of chromatic adaptation on achromaticity. Journal of the Optical Society of America, 38, 1025-1032.

Hirst, W. (1982). The amnesic syndrome: Descriptions and explanations. Psychological Bulletin, 91, 435-460.

Johnson, D. M. (1949). Learning function for a change in the scale of judgment. Journal of Experimental Psychology, 39, 851-860.

Johnson, M. K., Kim, J. K., \& Risse, G. (1985). Do alcoholic Korsakoff's syndrome patients acquire affective reactions? Journal of
Experimental Psychology: Learning, Memory, and Cognition, 11, 22-36.

Julesz, B. (1971). Foundations of cyclopean perception. Chicago: University of Chicago Press.

Kaufman, L. (1974). Sight and mind. New York: Oxford University Press.

Lezak, M. D. (1983). Neuropsychological assessment. New York: Oxford University Press.

Long, L. (1937). A study of the effect of preceding stimuli upon the judgment of auditory intensities. Archives of Psychology, 30, 157.

MacCracken, P. J., \& Bourne, J. A. (1977). Experience and latency to achieve stereopsis: A replication. Perceptual and Motor Skills, 45, 261-262.

MacCracken, P. J., \& Hayes, W. N. (1976). Experience and latency to achieve stereopsis. Perceptual and Motor Skills, 43, 1227-1231.

Mahut, H., \& Moss, M. (1984). Consolidation of memory: The hippocampus revisited. In L. R. Squire \& N. Butters (Eds.), The neuropsychology of memory (pp. 297-315). New York: Guilford Press.

Mattis, S. (1976). Dementia rating scale. In R. Bellack \& B. Karasu (Eds.), Geriatric psychiatry (pp. 77-121). New York: Grune \& Stratton.

Milner, B. (1962). Les troubles de la memoire accompagnant des lesions hippocampiques bilaterales. [Memory impairment accompanying bilateral hippocampal lesions]. In Physiologie de l'hippocampe (pp. 257-272). Paris: Centre National de la Recherche Scientifique.

Mishkin, M., Malamut, B., \& Bachevalier, J. (1984). Memories and habits: Two neural systems. In G. Lynch, J. L. McGaugh, \& N. M. Weinberger (Eds.), Neurobiology of learning and memory (pp. 65-77). New York: Guilford Press.

Nissen, M. J., \& Bullemer, P. (1987). Attentional requirements of learning: Evidence from performance measures. Cognitive Psychology, 19, 1-32.

Osterrieth, P. (1944). Le test de copic d'une figure complexe. [The test of copying a complex figure]. Archives of Psychology, 30, 306356.

Pratt, C. C. (1933). Time errors in the method of single stimuli. Journal of Experimental Psychology, 16, 798-814.

Ramachandran, V. S. (1976). Learning-like phenomena in stereopsis. Nature, 262, 382-384.

Rey, A. (1964), L'examen clinique en psychologie. [The clinical exam in psychology]. Paris: Presses Universitaires de France.

Schacter, D. L. (1985). Multiple forms of memory in humans and animals. In N. M. Weinberger, J. L. McGaugh, \& G. Lynch (Eds.), Memory systems of the brain (pp. 351-379). New York: Guilford Press.

Schacter, D. L. (1987). Implicit memory: History and current status. Journal of Experimental Psychology: Learning, Memory, and Cognition, 13, 501-518.

Schacter, D. L. (in press). On the relation between memory and consciousness: Dissociable interactions and conscious experience. In H. L. Roediger \& F. I. W. Craik (Eds.), Varieties of memory and consciousness: Essays in honor of Endel Tulving. Hillsdale, NJ: Erlbaum.

Shimamura, A. P. (1986). Priming effects in amnesia: Evidence for a dissociable memory function. Quarterly Journal of Experimental Psychology, 38A, 619-644.

Squire, L. R. (1982). The neuropsychology of human memory. Annual Review of Neuroscience, 5, 241-273.

Squire, L. R. (1986). Mechanisms of memory. Science, 232, 16121619.

Squire, L. R. (1987). Memory and brain. New York: Oxford University Press. 
Squire, L. R., \& Shimamura, A. P. (1986). Characterizing amnesic patients for neurobehavioral study. Behavioral Neuroscience, 100 . 866-877.

Squire, L. R., Shimamura, A. P., \& Amaral, D. G. (in press). Memory and the hippocampus. In J. Byrne \& W. Berry (Eds.), Neural models of plasticity. New York: Academic Press.

Squire, L. R., \& Zola-Morgan, S. (1988). Memory: Brain systems and behavior. Trends in Neurosciences, 11, 170-175.

Thompson, R. F. (1986). The neurobiology of learning and memory. Science, 233, 941-947.

Tresselt, M. E. (1947). The influence of amount of practice upon the formation of a scale of judgment. Journal of Experimental Psychology, 37, 251-260.
Wechsler, D. (1987). Wechsler Memory Scale-Revised. San Antonio, TX: Psychological Corporation.

Weiskrantz, L. (1987). Neuroanatomy of memory and amnesia: A case for multiple memory systems. Human Neurobiology, 6, 93105.

Weiskrantz, L., \& Warrington, E. K. (1979). Conditioning in amnesic patients. Neuropsychologia, 17, 187-194.

Received February 16, 1988

Revision received April 28, 1988

Accepted May 12, 1988

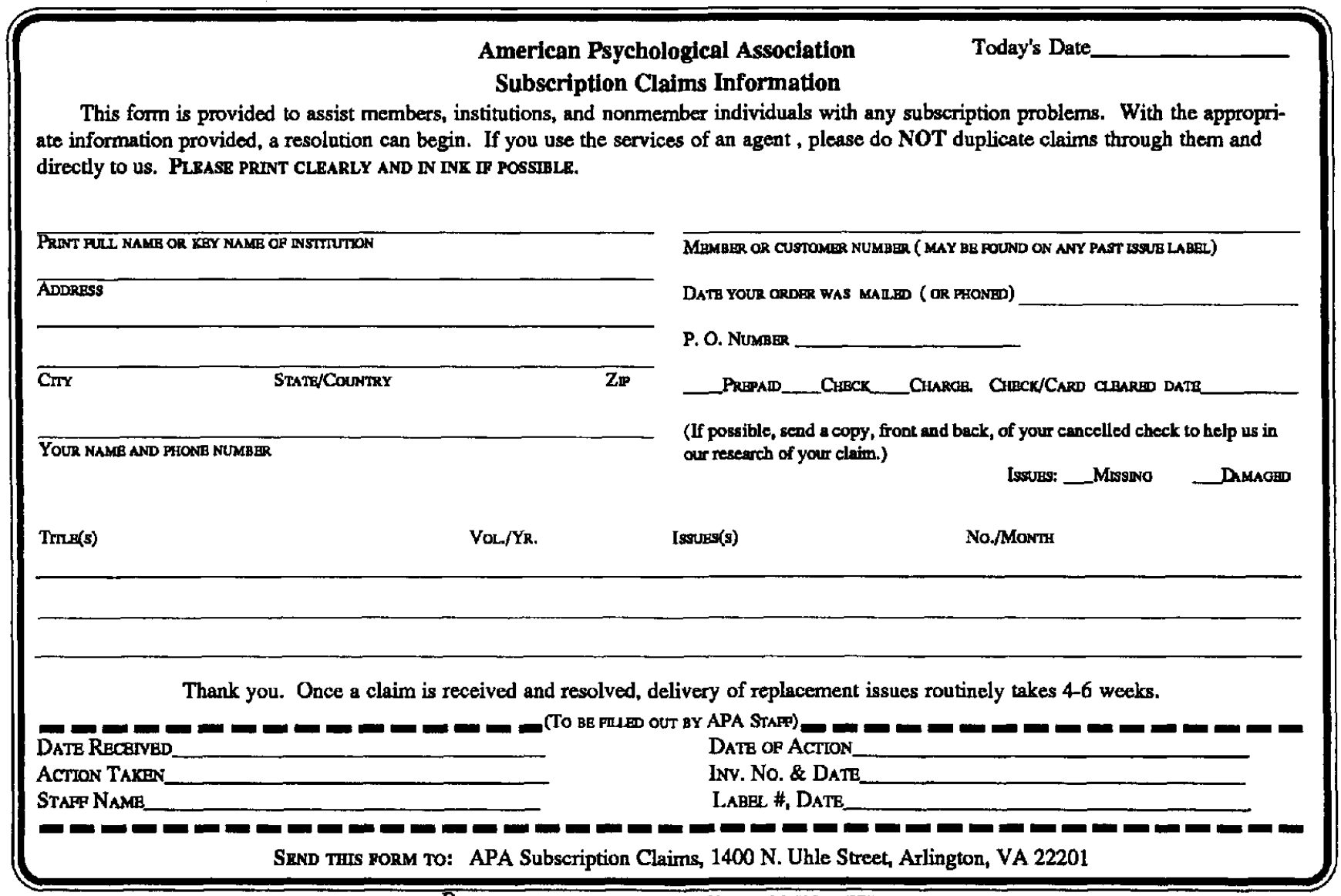

PLEASE DO NOT REMOVE. A PHOOTOCOPY MAY BE USED. 